\title{
BMJ Open Quality Resuming cataract surgery in a high-risk COVID-19 population
}

\author{
Haamed Al Hassan (D) , ${ }^{1}$ Adnaan Haq, ${ }^{2}$ Elizabeth Yang, $^{2}$ Evelyn Mensah ${ }^{2}$
}

To cite: Al Hassan $\mathrm{H}$, Haq A, Yang $\mathrm{E}$, et al. Resuming cataract surgery in a high-risk COVID-19 population. BMJ Open Quality 2021;10:e001116. doi:10.1136/ bmjoq-2020-001116

Received 15 July 2020 Accepted 18 May 2021

\section{Check for updates}

(C) Author(s) (or their employer(s)) 2021. Re-use permitted under CC BY-NC. No commercial re-use. See rights and permissions. Published by BMJ.

${ }^{1}$ Department of Anaesthesia, University Hospital of Wales, Cardiff, UK

${ }^{2}$ Ophthalmology Department, Central Middlesex Hospital, London North West University Healthcare NHS Trust, London, UK

Correspondence to

Dr Evelyn Mensah;

evelyn.mensah@nhs.net

\section{BACKGROUND}

Cataract surgery forms the bedrock of ophthalmic surgery in the UK as one of the most frequent, cost-effective, quality of life (QoL) enhancing procedures performed by the National Health Service (NHS). Elective cataract surgery was postponed at the start of the COVID-19 pandemic in March 2020. Restarting cataract surgery was a key milestone in returning to normalcy with uncertainty about COVID-19 disease duration. ${ }^{1}$ Disruption of services can have a severe impact on the QoL of our patients who are mostly elderly. The Royal College of Ophthalmologists published key principles addressing the restoration of services. ${ }^{2}$

Central Middlesex Hospital (CMH) serves Brent, a predominantly Black, Asian and Minority Ethnic population with high morbidity and mortality risk from COVID-19. ${ }^{3}$ Many preprint articles suggested increased risk of hospitalisation, admission to the intensive care unit and death for people of Black and Asian ethnicity. ${ }^{4}$ Brent had 210.9 COVID-19 deaths per 100 000; the highest age-standardised rate in England and Wales during the first pandemic wave. ${ }^{5}$ In addition, the cataract complexity rate for patients operated at $\mathrm{CMH}$ is the highest in the country. ${ }^{6}$ Restarting elective surgery presented a major challenge for NHS London Trusts hit first by the pandemic with greatest impact. There was concern that patients may fear attending the hospital for routine procedures amidst these circumstances.

We describe our pilot quality improvement project designed to determine the feasibility of a patient-centric and safe approach to restarting local anaesthetic cataract surgery within a high-risk population during the first wave of the COVID-19 pandemic.

\section{METHOD}

Prior to starting, we assessed the following three factors from patients on our waiting list:
Table 1 Modified MeNTS scoring system that systematically integrates factors associated with greater severity of COVID-19 illness and COVID-19 transmission risk to facilitate triage and decisionmaking for medically necessary, time-sensitive procedures (MeNTS)

\section{COVID risk score: modified MeNTS}

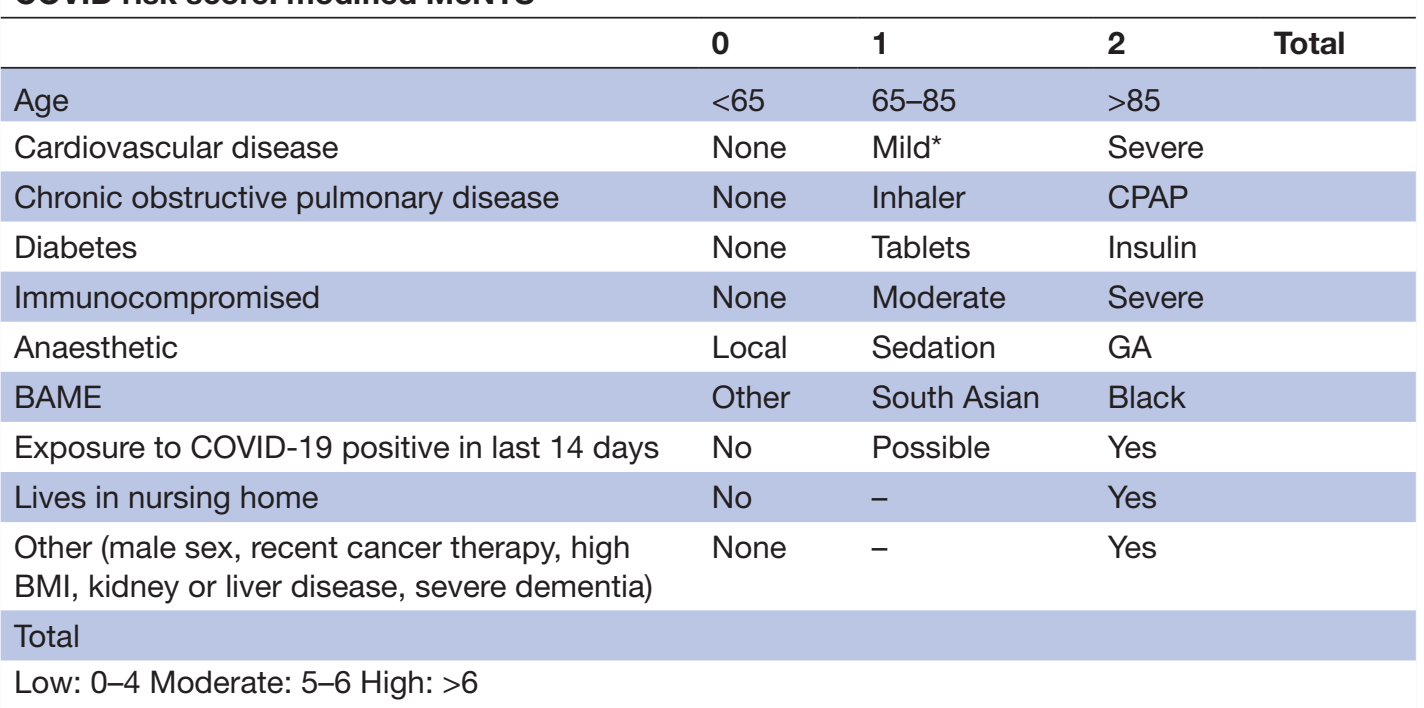

Adapted from Prachand et al 2020,.

${ }^{*}$ On medication only

BAME, Black, Asian and Minority Ethnic; BMI, body mass index. 
First, the Activities of Daily Living (ADL) score modified from a cataract assessment tool. Second, the modified Medically Necessary Time-Sensitive (modified-MeNTS) score (table 1) to determine the risk of morbidity and mortality from COVID-19 infection, ${ }^{7}$ and third, the cataract complexity score, ${ }^{2}$ to establish surgical risk. Effective prioritisation during this period of uncertainty was based on a high ADL score (ie, significant visual symptoms affecting QoL) and low modified-MeNTS score (ie, low COVID-19 risk). The cataract complexity score ensured a senior surgeon operated on the patient (figure 1; Step 1).

Appropriate patients were telephoned to explain the process and determine whether they still wished to proceed with cataract surgery. Reassurance was given to

\section{COMMENCEMENT OF CATARACT SURGERY}

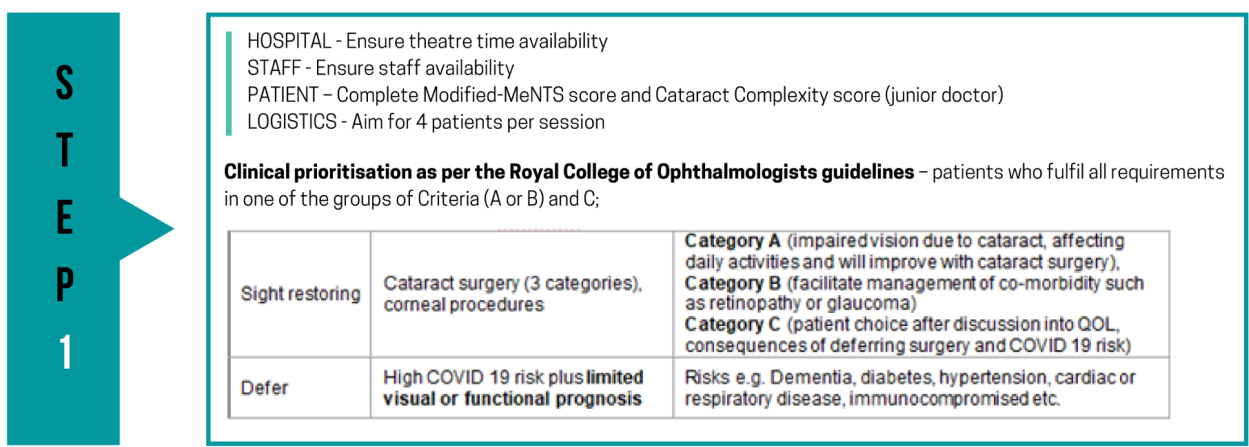

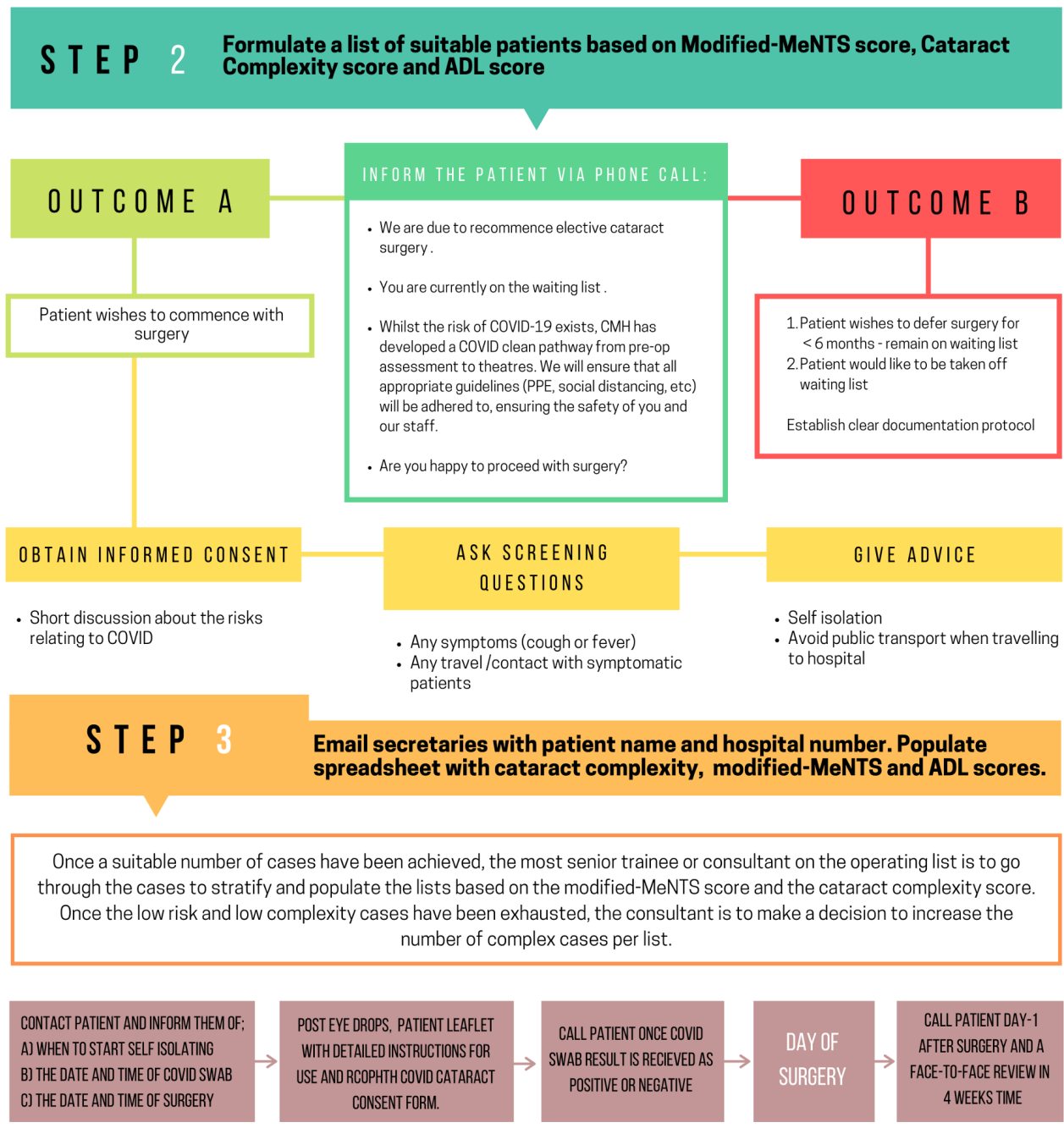

Figure 1 Commencement of cataract surgery flow chart describing the key steps in the process. ADL, Activities of Daily Living; $\mathrm{CMH}$, Central Middlesex Hospital; MeNTS, medically necessary, time-sensitive procedures. PPE, personal protective equipment 
patients about mitigating strategies in place designed to keep them and hospital staff safe. Patients that agreed to proceed were given a date for surgery and explanation about the COVID-protected pathway (figure 1; step 2). Informed consent was reconfirmed with additional information about COVID-19 infection risk. Patients that requested postponement remained on the waiting list with surgery deferred by 6 months and those requesting removal were taken off the waiting list (figure 1; outcome B).

Suitable patients with an allocated surgical date and time were informed to self-isolate for 7 days,. ${ }^{2}$ Patients were asked to avoid public transport when travelling to hospital for their COVID-19 nose and throat swabs 72 hours prior to surgery. Preoperative anaesthetic and dilating drops were given to the patients with clear instruction about self-instillation in the eye 1 hour before surgery. One day prior to surgery, patients were informed about their COVID-19 status, asked questions to ensure they had complied with self-isolation advice and had no COVID-19 symptoms. On the day of surgery, patients were admitted at staggered 1 hour intervals and had the final preoperative eye drops instilled. Following surgery, patients received a phone call the next day with postoperative review booked 4 weeks later.

\section{RESULTS}

One hundred seventeen patients on our waiting list were assessed of which 17 high-risk patients had their surgery deferred and eight eligible patients requested delay to their surgery. During a 10-week period commencing 17 June 2020, 94 patients underwent cataract surgery on 19 lists, with $100 \%$ attendance. Each 4 hours operating session was initially populated with four cases which subsequently increased to six cases per list. At the 4-week follow-up appointment, no patients had developed COVID-19 infection or symptoms and all patients showed objective and subjective vision improvement.

\section{CONCLUSION}

A combination of risk stratification, tele-consultation, COVID-19 testing, predilatation drops and staggered admissions resulted in successful and safe cataract surgery in a high-risk population. Our streamlined pathway and improved communication increased patient attendance from $86 \%$, just before the pandemic, to $100 \%$ through the pandemic. Inadvertently, CMH became the first unit in London to restart elective cataract surgery during the recovery phase of the initial pandemic wave. Our pilot demonstrates that elective cataract surgery can restart and continue safely despite the global pandemic. Subsequently, mutual aid was implemented in our unit to manage the cataract backlog in our sector.

Acknowledgements The authors would like to thank all staff working in the ophthalmology department and ACAD day surgical unit of Central Middlesex hospital. NB. While we have used the term 'BAME', we acknowledge the limitations of this acronym within different ethnic groups.

Contributors HAH: conception of the project, data acquisition, writeup, revision. AH and EY: conception of the project, data acquisition, revision. EM: conception of the project, revision, final approval, supervision.

Funding The authors have not declared a specific grant for this research from any funding agency in the public, commercial or not-for-profit sectors.

Competing interests None declared.

Patient and public involvement Patients and/or the public were not involved in the design, or conduct, or reporting, or dissemination plans of this research.

Patient consent for publication Not required.

Provenance and peer review Not commissioned; externally peer reviewed.

Open access This is an open access article distributed in accordance with the Creative Commons Attribution Non Commercial (CC BY-NC 4.0) license, which permits others to distribute, remix, adapt, build upon this work non-commercially, and license their derivative works on different terms, provided the original work is properly cited, appropriate credit is given, any changes made indicated, and the use is non-commercial. See: http://creativecommons.org/licenses/by-nc/4.0/.

ORCID iD

Haamed Al Hassan http://orcid.org/0000-0002-6640-9293

\section{REFERENCES}

1 Nicola M, O'Neill N, Sohrabi C, et al. Evidence based management guideline for the COVID-19 pandemic - Review article. Int J Surg 2020;77:206-16.

2 RCOphth: guidance on the resumption of cataract services during COVID, 2020. Available: https://www.rcophth.ac.uk/wp-content/ uploads/2020/05/Resumption-of-Cataract-Services-During-COVID-1. pdf

3 Pareek M, Bangash MN, Pareek N, et al. Ethnicity and COVID-19: an urgent public health research priority. Lancet 2020;395:1421-2.

4 Pan D, Sze S, Minhas JS, et al. The impact of ethnicity on clinical outcomes in COVID-19: a systematic review. EClinicalMedicine 2020;23:100404.

5 Office for National Statistics. Deaths involving COVID-19 by local area and socioeconomic deprivation: deaths occurring between 1 March and 31 may 2020, 2020. Available: https://www.ons.gov.uk/peoplepo pulationandcommunity/birthsdeathsandmarriages/deaths/bulletins/ deathsinvolvingcovid19bylocalareasanddeprivation/deathsoccurringb etween1marchand31may2020 [Accessed Jun 2020].

6 National Ophthalmology Database Audit 2019. The Royal College of ophthalmologists, 2019. Available: https://www.nodaudit.org.uk/u/ docs/20/urxqilwxmv/NOD\%20Audit\%20Annual\%20Report\%202019. pdf [Accessed Jun 2020].

7 Prachand VN, Milner R, Angelos P, et al. Medically necessary, TimeSensitive procedures: scoring system to ethically and efficiently manage resource scarcity and provider risk during the COVID-19 pandemic. J Am Coll Surg 2020;231:281-8. 